BLS 35, No 1 2009. DOI: http://dx.doi.org/10.3765/bls.v35i1.3613

(published by the Berkeley Linguistics Society and the Linguistic Society of America)

\title{
So Close Yet So Far: External Possessors in German and Estonian*
}

\author{
SILKE LAMBERT \\ University at Buffalo (SUNY)
}

\section{Introduction}

This paper studies external possession in two typologically unrelated languages, German (Indo-European) and Estonian (Finno-Ugric). External possession is a configuration in which a possessor is realized outside the NP headed by the possessum noun and appears as a verbal argument or adjunct (cf. König and Haspelmath 1998, Payne and Barshi 1999). Examples (1) for German and (2) for Estonian show the contrast between NP-internal (a) and external (b) possession.

\section{a. Maria hat Paul-s Hemd zerrissen. Maria has Paul-GEN shirt tear_apart.PTCPL 'Maria tore Paul's shirt.'}

b. Maria hat dem Paul das Hemd zerrissen. Maria has DEF.MASC.DAT Paul DEF.NEUT.ACC shirt tear_apart.PTCPL 'Maria tore Paul's shirt apart (on him).'

Lit.: 'Maria tore the shirt apart to Paul.'
a. Mari tõmba-s Erki särgi katki.
Mari pull-PAST Erki.GEN shirt.SG.GEN broken
'Mari tore Erki's shirt apart.'
b. Mari tõmba-s Erki-l särgi katki.
Mari pull-PAST Erki.ADESS shirt.SG.GEN broken
'Mari tore Erki's shirt apart.'
Lit.: 'Mari tore the shirt apart on Erki.'

These data illustrate that the German marker for external possessors (EPs) is the dative case, whereas in Estonian it is the adessive, a spatial case otherwise encoding stative location on surfaces. Apart from the case difference, the two EP constructions exemplified by the b. sentences look very similar. This study shows

\footnotetext{
* The research discussed in this paper was carried out in 2008 and funded by a grant from the Graduate Student Association, University at Buffalo. I would like to thank Liisa Melendez for the Estonian data, and Jürgen Bohnemeyer for his guidance. All errors, of course, are my own.
} 
Silke Lambert

that the similarity is a purely structural one, because in terms of meaning, the constructions are in fact remarkably different.

\section{General Overview of the German Dative and Estonian Adessive}

Before discussing the external possession data in section 2, this section will provide some background facts on the two case forms involved. The German dative has as its basic function the marking of indirect objects (or, from a semantic perspective, recipient participants in transfer events), as illustrated in (3). The Estonian adessive cannot encode this function, as shown in (4); rather, a different spatial case which encodes motion, the allative, is used.

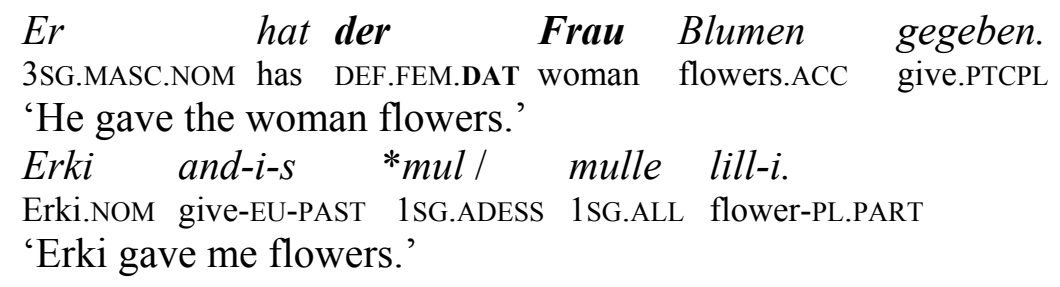

The Estonian adessive, on the other hand, can be used in basic locative constructions to express the ground (see (5)) without a mediating adpositional element. As (6) shows, this is impossible for the German dative, which cannot express spatial relations without a preposition.

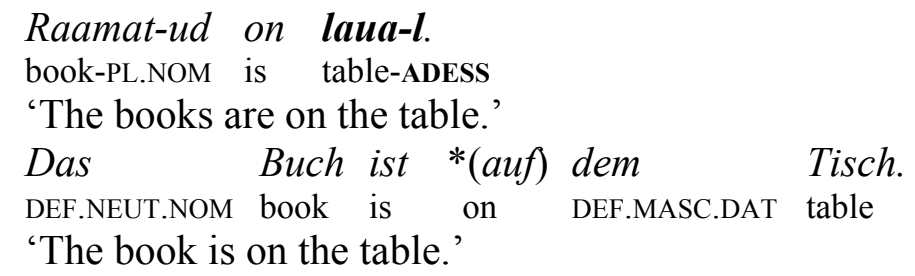

In addition to the basic functions of marking indirect objects (dative) and locative grounds (adessive), both cases can be used, quite similarly, to encode a participant who is indirectly or peripherally involved in an event, as in (7)/(8):

$$
\begin{aligned}
& \text { Das Publikum ist mir eingeschlafen. } \\
& \text { DEF.NEUT.NOM audience is 1SG.DAT fall_asleep.PTCPL } \\
& \text { 'The audience fell asleep on me [e.g., while I was lecturing].' } \\
& \text { Mul jäi publik maga-ma. } \\
& \text { 1SG.ADESS remain.PAST audience sleep-INF } \\
& \text { 'My audience fell asleep [e.g. when I was lecturing].' }
\end{aligned}
$$

Apparent translation equivalents like the pair in (7) and (8) suggest that the non-spatial adjunct uses of the adessive have the same functions as German adjunct datives. Accordingly, the label 'adessive-dative' was coined for these uses by Matsumura (1997 and prev.). No research to date has questioned this functional similarity; this is the aim of this paper. 
EP marking is a subset of the 'indirectly involved participant' function that the Estonian adessive and the German dative share. Moreover, it seems that not only are the constructions structurally similar, but, also, there is considerable overlap in their use and interpretation. We can see this in (1b) and (2b) above, which both describe the event of someone's shirt being torn: both sentences have the stereotypical reading that the possessor was wearing the shirt while this happened. They sound less natural if the possessor was not physically present in the event. It thus seems that the use of both the German EP dative and the Estonian EP adessive is governed by similar conditions: both are most naturally understood as descriptions of events in which possessor and possessum are spatially close to each other. Further scrutiny, however, shows that the underlying semantic factors are not so similar. These factors are explored in the next section.

\section{How Similar Are They Really?}

With respect to the semantic properties of EP constructions, much work has been done on German-type EP datives, as similar constructions occur in a number of Central and Southern European languages (see Haspelmath 1999, König and Haspelmath 1998 for general overviews). Several semantic restrictions on these dative constructions have been identified. The three most important ones are:

1. Animacy of the possessor.

2. Inalienable possession/spatial proximity of possessor and possessum.

3. Aktionsart: telic event descriptions.

In the following, the Estonian and German EP constructions will be compared with respect to these three factors. The data are organized in groups of event types: in section 2.1, EP constructions in resultative - and thus telic - event descriptions will be discussed, with varying degrees of animacy and alienability; in section 2.2, EP constructions in descriptions of activities - without a change of state, but non-stative; and in section 2.3 , states.

\subsection{EP Constructions in Telic/Resultative Event Descriptions}

We have already seen examples of EP constructions with telic event descriptions in (1b) and (2b) above (someone's shirt being torn). The examples to follow are similar in that they feature an event of breaking, another change of state with a clearly identifiable result. This event is kept constant throughout the examples, while the varied parameters are possessor animacy and alienability. First, we look at an animate possessor and an alienable possessive relation (a person and his cup; $(9 \mathrm{a}) /(11 \mathrm{a}))$, then, at an inanimate possessor of which the possessum is a part, rendering the relation inalienable (a cup and its handle; (9b)/(11b)).

Unsurprisingly, the acceptability judgments for German are in line with the generalizations on European EP constructions listed above: if the possessor is a person, it can be expressed as a dative EP even if the possessive relation is alienable (9a). If, however, the possessor is inanimate, then the EP construction is slightly odd, even for the inalienable relation between the cup and its handle (9b). 
Silke Lambert
a. Maria mach-te dem Paul die
Maria make-PAST DEF.MASC.DAT Paul 'Maria broke Paul's cup.'
b. \#Maria mach-te der Tasse den Henkel kaputt. Maria make-PAST DEF.FEM.DAT cup DEF.MASC.ACC handle broken
'Maria broke the cup's handle.'

Although (9b) is not ungrammatical, it is pragmatically inappropriate in most contexts, as indicated by the '\#' symbol. The sentence is almost inevitably interpreted as assigning human traits to the cup, such as the ability to suffer from having its handle broken. This is contrary to fact, but the sentence could well be used in a humorous way if personification is intended. Thus, German EP datives can evoke an anthropomorphic interpretation for inanimate referents, which shows that an integral part of their meaning is personal affectedness. ${ }^{1}$

The same result emerges from closer scrutiny of (9a). Obviously, we cannot observe a personification effect here since the dative referent is already animate; but it must be noted that the sentence does in fact not entail actual possession. It could well be someone else's cup, not Paul's, which Maria broke, as long as the event has some sort of negative or positive consequence for Paul. In (10), an NPinternal possessor is added to illustrate this. The dative, then, no longer encodes an EP, but rather a beneficiary or maleficiary.

$$
\begin{aligned}
& \text { Mariamach-te dem Paul Peter-s Tasse kaputt. } \\
& \text { Maria make-PAST DEF.MASC.DAT Paul Peter-GEN cup broken } \\
& \text { 'Maria broke Peter's cup on/for Paul.' }
\end{aligned}
$$

The crucial point about (9a) is that the sentence does not exclude an interpretation analogous to (10), and is thus not necessarily understood as an EP construction. It is, however, necessarily understood as evaluating the event as either good or bad for Paul, regardless of whether or not he owns the cup.

If we now turn to Estonian and its EP adessives mirroring the German EP datives in (9), we find the acceptability contrast reversed. For a human possessor and an alienable, mobile possessum (11a), acceptability is limited and strongly context-dependent, whereas with an inanimate possessor in an inalienable possessive relation, the construction is inconspicuous (11b).
a. \#Mari teg-i Erki-l tass- $i$ katki. Mari.NOM make-PAST Erki-ADESS cup-SG.GEN broken 'Mari broke Erki's cup.'
b. Mari murd-i-s tass-i-l sang-a.
Mari.NOM break-EU-PAST cup-EU-ADESS handle-SG.GEN
'Mari broke the cup's handle.'

\footnotetext{
${ }^{1}$ This has been claimed for the German dative in general; cf., e.g., Wegener (1985).
} 


\section{External Possessors in German and Estonian}

Regarding (11a), the only context to which this sentence is applicable is one in which the possessor is present in the event. (11a) can thus only be interpreted as describing a scene in which Erki was holding on to the cup while Mari broke it. The German sentence lacks this restriction, even though we saw earlier that similar event descriptions (like someone's shirt being torn) do show a preference for spatial proximity of possessor and possessum. It now emerges that this preference is even stronger in Estonian. Affectedness, on the other hand, does not play a role: whether the event of the cup being broken is good, bad, or neutral for Erki has no bearing on the acceptability of (11a), nor does the sentence itself suggest any negative or positive evaluation of the event.

Similar observations can be made about (11b). In this case, spatial proximity is trivially given because the possessum is a part of the possessor; but, being inanimate, this possessor cannot be construed as affected. Unlike its German counterpart, (11b) does not evoke personification of the cup, but is a natural way to describe the event of the cup's handle being broken. Not just affectedness, but animacy in general is thus irrelevant to the Estonian EP adessive.

From the discussion of EP constructions with telic events, we can conclude that there are substantial differences between the German EP dative and the Estonian EP adessive constructions, similar as they look at first sight: animacy, as the prerequisite for experiencing an event as good or bad, is crucial for the use of the German EP dative, and is even evoked metaphorically for inanimate referents. For Estonian, on the other hand, spatial proximity is a much more important factor. The discussion of further event types will corroborate these preliminary findings.

\subsection{EP Constructions in Atelic Event Descriptions (Activities)}

Here we focus on animate possessors (since inanimate ones can be expected to generally disallow the EP dative in German, as we saw above) with varying degrees of alienability. The following considerations motivate this: for German, we saw above that for animate possessors in telic events that involve a drastic change of state in the possessum, alienability is irrelevant to acceptability (recall Paul and his broken cup); but if the event itself has less of a physical impact and the possessor is therefore not affected through a change of state in the possessum, it is reasonable to hypothesize, in light of the criteria listed at the beginning of this section, that alienability does influence acceptability. For Estonian, where it has become apparent that spatial proximity is relevant, we may wonder how this effect is enhanced or reduced if the possessum does not undergo a change of state.

The activity chosen for the comparison is an event of someone looking at the possessum; the possessa are body parts (legs), items of clothing (shoes), and, as the least inalienable item, a picture of the possessor. For these three degrees of alienability, we observe a decline in acceptability for the EP construction in German. An event of someone looking at someone else's legs permits an EP description without difficulty (12a); if someone looks at someone else's shoes, the EP description is strange and strongly context-dependent (12b); and for the

picture scenario, it is hardly possible at all. In fact, (12c) can only be understood 
Silke Lambert

as describing a scene in which Paul looks at a picture that Maria is painting, and Paul's looking at it disturbs her. It is inappropriate as the description of Paul looking at a picture showing Maria, when she isn't involved in the event herself.

$$
\begin{aligned}
& \text { a. Paul schau-te der } \begin{array}{l}
\text { Maria auf die } \\
\text { Paul look-PAST DEF.FEM.DAT Maria on DEF.PL.ACC legs }
\end{array} \\
& \text { 'Paul looked at Maria's legs.' } \\
& \text { b. \#Paul schau-te der } \\
& \text { Paul look-PAST DEF.FEM.DAT Maria on DEF.PL.ACC }
\end{aligned}
$$

Clearly, personal affectedness of the possessor is the crucial factor in the use of EP constructions here. This becomes even more obvious if one considers the pragmatic circumstances that favor an utterance like (12a) or, even more so, (12b). Both sentences evoke the interpretation that Paul's looking was blatant, inappropriate, undesired or rude: (12a) would be the perfect description of Paul unashamedly checking out Maria's physical appearance, whereas (12b), although less natural, might be said if Paul stared at Maria's shoes with impolite intensity and/or Maria did not want her shoes to be seen. In both cases, Paul's looking is an intrusion into Maria's personal sphere, in which the respective possessum is located. The importance of personal sphere in the use of the German dative has been recognized by various linguists (cf. König and Haspelmath 1998:531ff., Dąbrowska 1997:16ff.); suffice it to say here that, if the event itself does not involve any sort of change in the possessum, the possessor's affectedness can be determined through the personal sphere: if the possessum is located within it, then the possessor can be conceptualized as affected, which licenses the EP dative construction. If it is not - as in the case of the possessor's picture - then the EP construction is infeasible. Note that the possible interpretation of (12c) as 'Paul looked at the picture Maria was painting' can be accounted for along these lines as well, if the objects a person handles are considered part of the personal sphere.

For Estonian EP constructions, we have seen that spatial proximity is crucial; it is thus a viable hypothesis that acceptability ratings are similar to German, since the personal sphere can of course be interpreted in a purely spatial way as the region surrounding the possessor. It turns out, however, that all three degrees of alienability lead to perfectly acceptable sentences.

$$
\begin{array}{lll}
\text { a. Erki vaata-s } & \text { Mari-l } & \text { jalgu. } \\
\text { Erki.NOM look_at-PAST Mari-ADESS } & \text { leg.PL.PART } \\
\text { 'Erki looked at Mari's legs.' } & \\
\text { b. Erki vaata-s } & \text { Mari-l } & \text { jalanõus-id. } \\
\text { Erki.NOM look_at-PAST Mari-ADESS } & \text { shoe-PL.PART } \\
\text { 'Erki looked at Mari's shoes.' } &
\end{array}
$$




\section{c. Vaata-s-in ta-l Orkut-is pilt-e $k a, \ldots$ look_at-PAST-1SG 3SG-ADESS Orkut-INESS picture-PART too 'I also looked at her picture on Orkut, $[. .$.$] '2$}

For the body part (13a) and the item of clothing (13b), acceptability is expected, since these possessa are naturally close to the possessor. The picture showing the possessor, as in (13c), is not; it is just the possessor's image - an iconic sign representing her - that is spatially associated with the picture. Furthermore, the sentence, taken from an online discussion, refers to the picture on someone's profile on a networking website. Since the picture is a part of the profile, and the profile can be said to metonymically represent its owner, spatial proximity can also be said to be given metonymically. We can thus assume that this 'indirect,' either iconic or metonymical, presence of the possessor licenses the use of the EP adessive - in contrast to situations in which even this indirect proximity is lacking, like when someone's cup is broken (see (11a) above).

To conclude, the discussion of EPs with activity descriptions confirms and refines the initial findings on telic event descriptions: for German, where animacy has been found to be a crucial parameter licensing the EP dative, we have seen that the possessor's personal sphere plays a role as well. However, as the contrast with the Estonian data shows, this sphere is not merely the spatial region surrounding a person, but, rather, a region of minimal distance necessary for personal comfort; any intrusion into this region will cause discomfort. Such discomfort is a kind of negative affectedness and, therefore, licenses the use of an EP dative.

In Estonian, on the other hand, we see again that spatial proximity of possessor and possessum is the relevant factor, even if it is only indirect iconic/metonymical. It thus seems that the Estonian EP adessive is acceptable for all kinds of possessors and all kinds of event descriptions, as long as there is some, however non-literal, way to interpret possessor and possessum as spatially close.

\subsection{EP Constructions in State Descriptions}

With states which have minimal capacity of inducing any sort of affectedness, we expect the German EP dative to be largely excluded. For Estonian, however, there is no reason for unacceptability under the condition of (indirect) spatial proximity.

The variation in the following examples is, again, in two variables: the nature of the possessive relationship (alienable/inalienable) and the way the state is experienced. The former parameter might be relevant to the Estonian EP construction, since inalienability is related to spatial proximity. The latter, the subjective evaluation of the state, may influence acceptability of the German EP construction: the three states predicated of the possessum in the examples, being dead, being sick and being dirty, are all likely to be perceived as negative by the posses-

\footnotetext{
${ }^{2}$ http://board.koffer.ee/viewtopic.php?p=1814139\&sid=351f9962c7f84cf2b367f11 d5053d177
} 
Silke Lambert

sor and thus affect her; so if German allows any EP datives with state descriptions at all, it should be with states like these. As shown in (14), however, this prediction is only partially borne out.
a. $*$ Der
Goldfisch war DEF.MASC.NOM goldfish was
ihm
tot. intended: 'His goldfish was dead.'
b. ?Die
Mutter war ihm
DEF.FEM.NOM
mother was
krank
'His mother was sick.'
3SG.MASC.DAT dead
c. ${ }^{*} \boldsymbol{I h m}$ ist das Hemd dreckig.
3SG.MASC.DAT is DEF.NEUT.NOM shirt dirty
intended: 'His shirt is dirty.'

The acceptability judgments for (14) show that the only context for which the EP dative is marginally acceptable with a state description is the case of kin as possessum (14b). It is unacceptable with other possessa, even if the state predicated of the possessum is something as grave and irreversible as being dead (14a). Here, the affectedness necessary for the EP dative construction is brought about only by a combination of inalienability and negative evaluation of the state - the presence of just one of these two parameters is insufficient.

In Estonian, on the other hand, all three states are compatible with an EP:
a. Erki-l kuldkala ol-i surnud. Erki-ADESS goldfish be-PAST dead 'Erki's goldfish was dead.'
b. Ta-l on ema haige. 3sg.ADESS be.PRES mother sick 'His mother is sick.'
c. Erki-l on särg must.
Erki-ADESS is shirt.SG.NOM black
'Erki's shirt is dirty./Erki has his shirt dirty.'

The unconditional acceptability of these three EP constructions is a little surprising, since the situations they describe do not necessarily involve spatial closeness between possessor and possessum. Neither can we observe iconic or metonymical proximity, as discussed above for EP adessives with activity verbs. Note, however, that the specific construction shared by the examples in (15), a possessor-denoting adessive accompanying the copula olema 'be,' is in fact the Estonian strategy to express possessive predication ('A has B'). The next section will address this correspondence in more detail. Suffice it to say here that the data in (15) cannot be unambiguously categorized as EP constructions, since they have the same structure as possessive predication.

\footnotetext{
${ }^{3}$ This is not entirely true, since body-part possessa may allow EP datives with states as well (e.g., in the collocation Ihm ist das Herz schwer 'his heart is heavy', lit. 'to him the heart is heavy'). But as both kin and body parts are inalienably possessed, this fact does not affect the discussion.
} 
To conclude this section, let us briefly review the comparison of the Estonian and German data. The translation equivalents of the EP constructions in the two languages do not show identical acceptability values when semantic parameters like event type, animacy, and alienability are varied; rather, we have seen that animacy and, moreover, personal affectedness are crucial for the EP dative in German, whereas Estonian seems to require spatial proximity (albeit in a possibly non-literal sense) of possessor and possessum to render the EP adessive feasible. In short, the data show clearly that, similar as the two constructions may look from a purely structural point of view, they have entirely different semantic properties. What semantic categories, then, are we dealing with here? The following section addresses this question and provides a semantic categorization for each of the EP constructions under discussion.

\section{Affectedness Construction vs. Spatial Metaphor}

To corroborate the diverging semantic analyses for the German and Estonian EP constructions that the comparison in the previous section suggests, it is desirable to find additional uses of the two cases (dative and adessive, respectively) that do not involve external possession, but do exhibit the same semantic properties that have been identified for their EP uses. The fact that such uses exist has already been hinted at in the above discussion: German has dative constructions that express affectedness without possession, which renders it plausible that the EP dative is really just a subtype of a general affectedness dative. Estonian, on the other hand, employs the adessive to express possession in predicative constructions, which suggests that, in this language, possession is treated as a spatial metaphor.

The following example illustrates a general affectedness configuration without possession. (16) shows a German dative encoding a maleficiary, a negatively affected participant, which the Estonian adessive cannot express (see (17)).

(16) [Context: Paul was telling Maria a story.]

Maria ist ihm eingeschlafen!

Maria is 3SG.MASC.DAT fall_asleep.PTCPL

'Maria fell asleep on him (it was rude to him).'

[Context: as in (16)]

\#Mari jäi Erki-l maga-ma.

Mari.NOM remain.PAST Erki-ADESS sleep-INF

intended: 'Mari fell asleep and it was rude to Erki.'

In Estonian, the only way to interpret the sentence is as a literal spatial description: Mari fell asleep on top of Erki. The German dative in (16), however, is naturally understood as marking its referent as a participant for whom the event is either good or bad - in the given context, the latter. Since no possession is involved (the dative referent does not possess anything mentioned or implied in the sentence) this example indicates that the German dative in general, not just as an EP marker, can portray an event participant as positively or negatively affected. 
Silke Lambert

Affectedness constructions have been studied by Smith (2005), who shows that many languages single out particular formal or structural configurations to express benefit or adversity. This kind of positive or negative evaluation of events is thus a feature of grammatical relevance. The dative case in many IndoEuropean languages, including German, is a prominent example in her discussion, and the findings of the present study are in line with her analysis.

Turning to non-EP (and non-spatial) uses of the Estonian adessive, we have seen above that this case form is involved in possessive predication. This construction takes the form of a locative predication and features the copula verb olema 'be,' the possessum in the nominative and the possessor in the adessive case, conveying a literal meaning of 'POSSESSUM is on/at POSSESSOR.' This holds for inalienable possessive relationships (18a) as well as for alienable ones (18b). As (19) shows, Standard German cannot mirror this construction with the dative. ${ }^{4}$

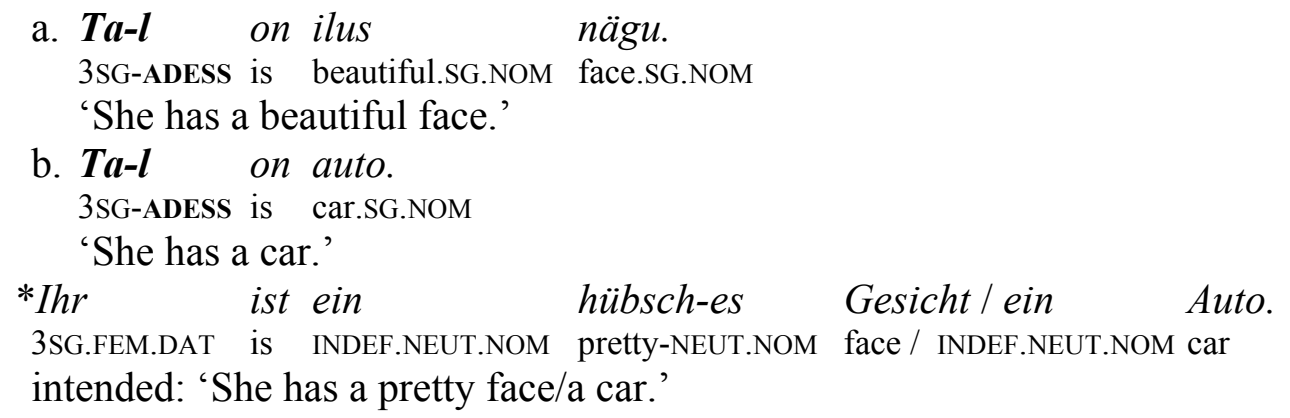

The Estonian strategy of expressing possession by means of a form that, in its basic function, encodes a spatial relation is cross-linguistically frequent (Stassen 2008) and can be accounted for by general cognitive principles (cf. Lakoff and Johnson 1980). According to these principles, spatial concepts can be extended to non-spatial domains, including possession, and spatial vocabulary is then used metaphorically to refer to these domains. We can conclude from these facts that the EP use of the Estonian adessive is really just a constructional extension of the adessive use in possessive predication: in both cases, possession is encoded metaphorically as a spatial relation - in the latter case, as the only available strategy, in the former, as an alternative to NP-internal possession featuring the genitive case. The extension of spatial concepts to non-spatial domains, then, is the underlying motivation for the EP adessive in Estonian.

If the semantic and cognitive factors that govern the use of the EP dative in German and adessive in Estonian are so different, we may ask why the two constructions are so strikingly similar, not only in their structural features but also, to a large extent, in their distribution and meaning. Let us look back at an earlier example, repeated below as (20) [German]/(21) [Estonian]. The two sentences seem to convey exactly the same implications: the speaker, encoded by

\footnotetext{
${ }^{4}$ Several dialects do allow the construction illustrated in (19). For reasons of limited space, these variants will not be considered here.
} 
dative/adessive respectively, is presented as an indirectly involved participant to whom the event is of some, presumably negative, relevance.

$$
\begin{aligned}
& \text { Das Publikum ist mir eingeschlafen. } \\
& \text { DEF.NEUT.NOM audience is 1SG.DAT fall_asleep.PTCPL } \\
& \text { 'The audience fell asleep on me [e.g. while I was lecturing].' } \\
& \text { Mul jäi } \quad \text { publik maga-ma. } \\
& \text { 1SG.ADESS remain.PAST audience sleep-INF } \\
& \text { 'My audience fell asleep [e.g. while I was lecturing].' }
\end{aligned}
$$

The differences between these two translation equivalents are subtle and only emerge in light of the preceding discussion. To start with the Estonian example (21), the notion of negative relevance is purely a result of the sentence context plus world knowledge: it is common sense that it is bad for a speaker or lecturer if her audience sleeps while she is talking. Exactly the same idea would arise from the internal possessor (IP) version of the sentence, with the possessor realized as an adnominal genitive ('my audience'). In terms of affectedness and how this interpretation comes about, there is thus no difference between the EP and IP constructions in Estonian. In German, however, the negative evaluation is transported by the dative. The sentence in (20) is not equivalent, in this respect, to its IP counterpart; rather, the IP version has the same properties as the Estonian example, whereas in (20), the EP dative specifies the semantic property of affectedness for its referent independent from, and in addition to, any context or world knowledge that may suggest it. The German EP dative construction, thus, makes an evaluative statement, which entails the affectedness of the dative referent by the event as part of its meaning. The Estonian construction, on the other hand, yields a neutral description, with any negative affectedness merely arising as an implicature.

\section{Summary and Conclusion}

This study has shown that the EP constructions in German and Estonian, similar as they look, have very different semantic properties. For German, the EP marker, the dative case, specifies positive or negative affectedness for its referent, a phenomenon that is also observed in non-possessive adjunct datives. This qualifies the German EP dative as an affectedness construction - or rather, as a subtype of a general affectedness dative construction, with possession a secondary component.

The Estonian EP adessive, on the other hand, lacks this semantic specification and yields neutral, non-evaluative descriptions. Although it portrays its referent, similarly to the German construction, as somehow indirectly involved, this effect arises merely from its spatial semantics - as well as possible implications from the sentence context and world knowledge. Since the adessive is a possessor marker in other contexts than external possession as well (in particular, possessive predication), we find that the EP adessive is simply a facet of the general strategy in Estonian to express possession as location.

The overall conclusion to be drawn from this comparison is that the label 'external possession' only applies to syntactic description. As this study illustrates, 
Silke Lambert

two constructions in two different languages that can both be identified, structurally, as EP constructions may have very different semantic properties. Therefore, on the semantic level, the label 'external possession' is not applicable; other categories are necessary to describe the meanings of these constructions appropriately and account for the subtle differences that elude a purely structural approach. In the present study, the German EP dative has been classified as an affectedness construction, the Estonian EP adessive as a spatial metaphor. EP constructions in other languages might involve further semantic categories, which remain to be explored.

\section{References}

Dąbrowska, Ewa. 1997. Cognitive semantics and the Polish dative. Berlin/New York: Mouton de Gruyter.

Haspelmath, Martin. 1999. External possession in a European areal perspective. In Payne and Barshi (1999), 109-135.

König, Ekkehard, and Martin Haspelmath. 1998. Les constructions à possesseur externe dans les langues d'Europe. In J. Feuillet, ed., Actance et valence dans les langues de l'Europe, 525-606. Berlin/New York: Mouton de Gruyter.

Lakoff, George, and Mark Johnson. 1980. Metaphors we live by. Chicago: University of Chicago Press.

Matsumura, Kazuto. 1997. The dative use of the adessive case in Estonian: A corpus-based study. In Kazuto Matsumura and Tooru Hayasi, eds., The dative and related phenomena, 31-79. Tokyo: Hituzi Syobo.

Payne, Doris, and Immanuel Barshi, eds. 1999. External possession. Amsterdam/ Philadelphia: John Benjamins.

Smith, Tomoko Yamashita. 2005. Affectedness constructions: How languages indicate positive and negative events. Ph.D. diss., UC Berkeley.

Stassen, Leon. 2008. Predicative possession. In Martin Haspelmath, Matthew Dryer, David Gil, and Bernard Comrie, eds., The world atlas of language structures online, Chapter 117. Munich: Max Planck Digital Library. http://wals.info/feature/description/117.

Wegener, Heide. 1985. Der Dativ im heutigen Deutsch. Tübingen: Narr.

Silke Lambert

University at Buffalo (SUNY)

Department of Linguistics

609 Baldy Hall

Buffalo, NY 14260

slambert@buffalo.edu 